\title{
Unplanned hospital transfers from nursing homes: who is involved in the transfer decision? Results from the HOMERN study
}

\author{
Alexandra Pulst $^{1,2}$ (D) Alexander Maximilian Fassmer ${ }^{3}$ (D) $\cdot$ Guido Schmiemann $^{1,2,4} \mathbb{D}$
}

Received: 11 September 2020 / Accepted: 30 October 2020 / Published online: 30 November 2020

(c) The Author(s) 2020

\begin{abstract}
Background Emergency department visits and hospital admissions are common among nursing home residents (NHRs) and seem to be higher in Germany than in other countries. Yet, research on characteristics of transfers and involved persons in the transfer decision is scarce.

Aims The aim of this study was to analyze the characteristics of hospital transfers from nursing homes (NHs) focused on contacts to physicians, family members and legal guardians prior to a transfer.

Methods We conducted a multi-center study in $14 \mathrm{NHs}$ in the regions Bremen and Lower Saxony (Northwestern Germany) between March 2018 and July 2019. Hospital transfers were documented for 12 months by nursing staff using a standardized questionnaire. Data were derived from care records and perspectives of nursing staff and were analyzed descriptively. Results Among 802 included NHRs, $n=535$ unplanned hospital transfers occurred of which $63.1 \%$ resulted in an admission. Main reasons were deterioration of health status (e.g. fever, infections, dyspnea and exsiccosis) (35.1\%) and falls/accidents/ injuries (33.5\%). Within $48 \mathrm{~h}$ prior to transfer, contact to at least one general practitioner (GP)/specialist/out-of-hour-care physician was $46.2 \%$ and varied between the NHs (range: $32.3-83.3 \%$ ). GPs were involved in only $34.8 \%$ of transfer decisions. Relatives and legal guardians were more often informed about transfer (62.3\% and 66.8\%) than involved in the decision $(21.8 \%$ and $15.1 \%)$.
\end{abstract}

Discussion Contacts to physicians and involvement of the GP were low prior to unplanned transfers. The ranges between the NHs may be explained by organizational differences.

Conclusion Improvements in communication between nursing staff, physicians and others are required to reduce potentially avoidable transfers.

Keywords Nursing home residents $\cdot$ Hospitalization $\cdot$ Hospital admission $\cdot$ Patient transfer $\cdot$ Emergency department . Decision making

Electronic supplementary material The online version of this article (https://doi.org/10.1007/s40520-020-01751-5) contains supplementary material, which is available to authorized users.

Alexandra Pulst

a.pulst@uni-bremen.de

1 Department for Health Services Research, Institute of Public Health and Nursing Research, University of Bremen, Grazer Straße 4, 28359 Bremen, Germany

2 Health Sciences Bremen, University of Bremen, 28359 Bremen, Germany

3 Department of Health Services Research, School VI, Medicine and Health Sciences, Carl von Ossietzky University of Oldenburg, Ammerländer Heerstraße 114-118, 26129 Oldenburg, Germany

4 Institute for General Practice, Hannover Medical School, 30625 Hannover, Germany

\section{Introduction}

Nursing home residents (NHRs) are characterized by multimorbidity and frailty [1]. Compared to community-dwelling older people, transfers to emergency department (ED) and hospital admissions are more frequent among NHRs [2-6]. The prevalence of transfers from nursing homes (NHs) ranges in international studies between $6.8 \%$ and $45.7 \%$ depending on the study design and different time periods of follow-up [5] and seem to be more common in Germany than in other Western countries [7-9]. Transfers can lead to adverse consequences like nosocomial infections, delirium or functional decline and high costs due to increased ambulance use and hospital treatment $[2,10]$. 
In Germany, medical care of NHRs is usually provided by general practitioners (GPs) [11].If specialized care is required, treatment in NHs can be provided by specialists. Elderly care physicians as in the Netherlands, for example [12] are an exception. In the case of health deteriorations outside of GPs' working hours, nursing staff can contact out-of-hour health care services (OOHC) in which every practicing physician is legally obliged to participate [13]. In Germany, the OOHC can be called by the nationwide phone number "116 117".In life-threatening cases, the Emergency Medical Service (EMS) is responsible and can be contacted to send out an ambulance ("112"). Even though there are several possibilities to manage health changes of NHR in outpatient care, ambulance calls increased in NHs over the last years $[14,15]$. In this context, several studies indicate that some hospitals transfers from NHs might be avoidable [16-18].

The process from the onset of health changes to the transfer decision is complex and can be influenced by different factors. Studies analyzing transfers of NHRs often follow a retrospective design [19-21]. In the literature individual factors (e.g. clinical conditions [2], degree of frailty [22], availability of advance directives (ADs) [23]), structural factors (e.g. staffing capacity [24, 25], access to equipment in $\mathrm{NH}$ [23], availability of physicians [10]) and communication deficits between nursing staff and physicians [23] are described as reasons for hospital transfers from NHs. Additionally, significant others such as family members and legal guardians can influence the transfer decision [26, 27].

So far, it is unclear how often physicians, family members and legal guardians are involved before an ambulance is called. This is especially relevant in unplanned transfers which can be initiated in Germany without prior medical order of a physician. As a result of this lacking reassurance, many ambulance calls can lead to hospital transports and admissions. Therefore unplanned transfers may be a major contributor for potentially avoidable hospital transfers from NHs. In Germany, evidence on characteristics of unplanned hospital transfers from NHs and involvement of others is scarce. Therefore, this study intends to close this gap in research. The aim was to explore the characteristics of unplanned hospital transfers from NHs and to analyze prior contacts to different health care providers and involvement of others in the transfer decision.

\section{Methods}

\section{Study design}

We used data from the project 'HOspitalisations and eMERrgency department visits of Nursing home residents' (HOMERN). In this project, we conducted a multi-center observational study in NHs providing long-term care in Northwestern Germany. The convenience sample consisted of NHs in the region to which we had personal contacts and/or who had participated in former research projects and further facilities. They differed in size (numbers of beds), ownership (non-profit and private for-profit) and location (rural and urban) to achieve heterogeneity. All NHs were located in the federal state Bremen and surrounding Lower Saxony (Northwestern Germany). Because we focused on long-term care NHs, we excluded short-term care units in this study. We further excluded NHs that offered specialized care only (e.g. for residents with dementia) to reduce the risk of selection effects and overestimation of dementia in the study population. Participating $\mathrm{NHs}$ were asked to include either all residents of the whole $\mathrm{NH}$ or alternatively all residents living in selected care units. There were no exclusion criteria for the residents. In total, $n=49 \mathrm{NHs}$ were contacted for recruitment of whom $n=14 \mathrm{NHs}$ agreed to participate.

During a 12-month period, data on all (un)planned hospital transfers (including ED visits and hospital admissions) were collected in the 14 NHs from March 2018 to July 2019. Nursing staff (mainly nursing managers) in the NHs were responsible for data collection and trained to answer the questionnaire. Data included clinical information from medical records and the perspectives of nursing staff only. Informed consent was obtained from all participating NHs before the study started. Residents did not participate actively in the study. Ethical approval for this study was given by the ethics committee of the Medical Association of Bremen (RA/RE-613, 16 February 2018). This article followed the STROBE guidelines for reporting observational studies [28].

\section{Data collection and analysis}

Based on existing literature $[10,16,18,24,26,29]$ a standardized questionnaire was developed to collect characteristics of hospital transfers and persons involved in transfer decision. The questionnaire was pilot-tested with nursing managers in three NHs which also participated in the study later. Based on their comments the questionnaire was revised. Each NH assigned a contact person (mainly nursing managers) who was responsible for data collection and trained in the handling of the questionnaire prior to the study.

For each transfer nursing staff was asked to document: characteristics of the NHR (age, sex, marital status, duration of NH residence, frequency of transfers in the last 12 months), impairment in activities of daily living (BarthelIndex), and availability/content of ADs. As dementia is often 
underreported in medical records [30, 31], diagnosis and severity of dementia were assessed by nursing staff.

Characteristics of the transfer included date, time-slot, death during transfer/in hospital, the result of the transfer (ED visit/hospital admission), kind/duration of symptoms and date of discharge. Further, we assessed contacts to GPs, specialists, OOHC, EMS and emergency physicians in the last $48 \mathrm{~h}$ prior to transfer ('yes-via telephone' or 'yesvia NH visit' or 'no contact'). Involvement of the resident, family members and legal guardians in transfer decision was enquired using a 4-point Likert scale ('was involved in transfer decision', 'was informed about transfer', 'not contacted' or 'involvement unknown'). Family members and legal guardians could also be assessed as 'not existent'. The involvement of the GP in transfer decision was assessed by four categories: 'involved via NH visit', 'involved via telephone', 'not involved because not available', 'not involved because not contacted'. Data on size and staffing of NHs were not collected, as an individual analysis was not planned due to data confidentiality. Further open questions were used for assessment of symptoms (which were not covered by the given categories) and the specialization of an involved specialist. The staff was asked to fill out the questionnaire immediately after each transfer. For each documentation, a financial compensation of 10 Euro was paid. There was regular personal and telephone contact between researchers and NHs to ensure that all transfers were documented and that questionnaires were picked up regularly.

The data were descriptively analyzed using IBM SPSS Statistics 25 and SAS 9.4 (SAS Institute, Cary, USA). Because not all respondents answered every question in the questionnaire, the analyses of each question were based on subjects without missing values. Below, we report on unplanned hospital transfers only. An analysis considering also planned transfers is already published elsewhere [32].

\section{Results}

In total, $14 \mathrm{NHs}$ with $n=802$ residents were included. Mean number of included residents per $\mathrm{NH}$ was 57 (range: 26-114). During 12 months of follow-up, $n=626$ hospital transfers occurred. $\mathrm{N}=3$ transfers were excluded from data analysis because these residents died during transfer and no further information was provided. $85.9 \%$ of transfers were unplanned $(n=535)$. Median rate for unplanned transfers was 0.67 per resident and year.

\section{Characteristics of transferred NHRs}

Transferred residents were mainly female $(70.2 \%)$ and widowed (63.7\%). Mean age was 83.8 years (range:
49-103 years). Mean duration of $\mathrm{NH}$ residence was 2.4 years (see Table 1). More than half of the residents had one to three hospital transfers $(51.8 \%)$ in the last 12 months before study inclusion, $11.3 \%$ were transferred more than three times and $36.9 \%$ had not been hospitalized in the year before.

\section{Characteristics of unplanned transfers}

Transfers were nearly equally spread over the weekdays (ranges between $10.1 \%$ and $17.3 \%$ ) with a maximum on Mondays (17.3\%; $n=92) .24 .4 \%$ of transfers were initiated on weekends. NHRs were mainly transferred during the morning (36.9\%) or early afternoon (34.4\%) (Fig. 1).

Main reasons for transfer were a deterioration of health status including fever, infections, dyspnea and exsiccosis (35.1\%) and falls/accidents/injuries (33.5\%) (see Supplementary file 1). Most symptoms occurred in the $4 \mathrm{~h}$ prior to transfer (60.4\%) and in $14.7 \%$ the symptoms lasted more than $24 \mathrm{~h}$. In the majority of cases, transfers lead to admission $(63.1 \%$ ), while $36.9 \%$ of treatments were carried out in ED. Hospital admission were mainly required because of deterioration of health status (48.5\%), ED visits were mostly required because of falls/accidents/injuries (51.8\%).

\section{Contacts to health care provider $48 \mathrm{~h}$ prior to transfer}

$48 \mathrm{~h}$ prior to the transfer, nursing staff contacted the GP in $38.7 \%$ (via telephone only: $17.1 \%$; via NH visit: $21.6 \%$ ). The extent to which the GPs were consulted prior to transport differed between the underlying symptoms: GPs were mostly involved in case of a deteriorated health status $(52.1 \%)$, pain not induced by fall (51.5\%) and others symptoms like gastrointestinal symptoms or bleedings $(50.9 \%)$.

In $8.4 \%$ nursing staff contacted a specialist (only via telephone: $4.1 \%$; via NH visit: $4.3 \%$ ) and in $7.4 \%$ OOHC (only via telephone: $5.1 \%$; via $\mathrm{NH}$ visit: $2.3 \%$ ). Contact rate to at least one physician (GP, specialist, OOHC) was $46.2 \%$ and varied between the NHs (range: 32.3-83.3\%). In every fifth case (17.0\%), nursing staff called the EMS/emergency physician directly (see Table 2). In $44.5 \%$ no health care provider was contacted (range between NHs: 5.9-63.0\%). For further information see Table 2 (only transfers with prior contacts are displayed).

\section{Involvement in the transfer decision}

In two-thirds of the cases (65.2\%), the GP was not involved in the transfer decision-either because nursing staff did not try to contact him/her (38.3\%) or GP was not available (26.9\%). Between the NHs, this non-involvement varied 
Table 1 Characteristics of unplanned transferred nursing home residents $(n=535)$

\begin{tabular}{|c|c|c|}
\hline & & $N(\%)^{\mathrm{a}}$ \\
\hline \multirow[t]{3}{*}{ Sex } & Total & $(n=534)^{\mathrm{a}}$ \\
\hline & Male & $159(29.8)$ \\
\hline & Female & $375(70.2)$ \\
\hline \multirow[t]{7}{*}{ Age (years) } & Total & $(n=531)^{\mathrm{a}}$ \\
\hline & Mean (SD) & $83.8(9.3)$ \\
\hline & [range] & [49-103] \\
\hline & $0-69$ & $42(7.9)$ \\
\hline & $70-79$ & $95(17.9)$ \\
\hline & $80-89$ & $252(47.5)$ \\
\hline & $90+$ & $142(26.7)$ \\
\hline \multirow[t]{5}{*}{ Marital status } & Total & $(n=523)^{\mathrm{a}}$ \\
\hline & Widowed & $333(63.7)$ \\
\hline & Married/living in partnership & $95(18.2)$ \\
\hline & Single & $47(9.0)$ \\
\hline & Divorced/separate & $48(9.2)$ \\
\hline \multirow[t]{7}{*}{ Length of NH residence } & Total & $(n=518)^{\mathrm{a}}$ \\
\hline & Mean (SD) & $2.4(2.7)$ \\
\hline & [range] & {$[0-24]$} \\
\hline & $<1$ year & $200(38.8)$ \\
\hline & 1 to $<2$ years & $95(18.4)$ \\
\hline & 2 to $<3$ years & $67(12.6)$ \\
\hline & $\geq 3$ year & $156(30.2)$ \\
\hline \multirow[t]{6}{*}{ Dementia } & Total & $(n=532)^{\mathrm{a}}$ \\
\hline & No & $259(48.7)$ \\
\hline & Yes & $273(51.3)$ \\
\hline & Mild & $44(16.6)$ \\
\hline & Moderate & $124(46.8)$ \\
\hline & Severe & $97(36.6)$ \\
\hline \multirow[t]{8}{*}{ Barthel-Index (ADL) ${ }^{b}$} & Total & $(n=517)^{\mathrm{a}}$ \\
\hline & Mean (SD) & $43.3(24.9)$ \\
\hline & [range] & {$[0-100]$} \\
\hline & Slight/no dependency (score: $80-100$ ) & $43(8.3)$ \\
\hline & Mild dependency (score: 60-75) & $123(23.8)$ \\
\hline & Moderate dependency (score: 40-55) & $141(27.3)$ \\
\hline & Severe dependency (score: $20-35$ ) & $105(20.3)$ \\
\hline & Total dependency (score: $0-15$ ) & $105(20.3)$ \\
\hline \multirow[t]{3}{*}{ Residents' wish for end-of-life care } & Total & $(n=528)^{\mathrm{a}}$ \\
\hline & Unknown & $282(53.1)$ \\
\hline & Advance directive available & $249(46.9)$ \\
\hline
\end{tabular}

$N H$ nursing home, $A D L$ Activities of Daily Living

${ }^{a}$ Number differs due to missing values

${ }^{b}$ Based on ICD 10-GM Version 2016, see: https://www.dimdi.de/static/de/klassifikationen/icd/icd-10-gm/ kode-suche/htmlgm2016/block-u50-u52.htm (range: $5.9-73.9 \%$ because of no contact and $0.0-47.1 \%$ because of lacking availability). Related to the symptom duration, GPs were more often involved when symptoms lasted $24 \mathrm{~h}$ or longer $(71.8 \%)$ in contrast to symptoms lasting less than $4 \mathrm{~h}(17.7 \%)$. NHRs themselves were either involved in the decision $(45.8 \%)$ or only informed $(50.0 \%)$. In $93.7 \%$ $(n=472)$ NHRs had family members. These were involved in $21.8 \%$ (range between NHs: $7.1-55.5 \%$ ) or only informed 
Table 2 Contacts to physicians and other health care providers within 48 hrior to transfer- by resident and transfer characteristics ${ }^{\mathrm{a}}$

\begin{tabular}{|c|c|c|c|c|c|c|c|c|}
\hline \multirow{3}{*}{ Contacts prior to all transfers } & \multirow{2}{*}{\multicolumn{2}{|c|}{$\frac{\mathrm{GP}}{N}$}} & \multirow{2}{*}{\multicolumn{2}{|c|}{$\frac{\text { Specialist }}{N}$}} & \multirow{2}{*}{\multicolumn{2}{|c|}{$\frac{\mathrm{OOHC}}{N}$}} & \multirow{2}{*}{\multicolumn{2}{|c|}{$\frac{\mathrm{EMS} / \mathrm{EP}}{N}$}} \\
\hline & & & & & & & & \\
\hline & 206 & $(38.7 \%)$ & 45 & $(8.4 \%)$ & 39 & $(7.3 \%)$ & 91 & $(17.0 \%)$ \\
\hline By resident's sex & \multicolumn{2}{|l|}{$N=206$} & \multicolumn{2}{|l|}{$N=45$} & \multicolumn{2}{|l|}{$N=39$} & \multicolumn{2}{|l|}{$N=91$} \\
\hline Male & 56 & $(35.4 \%)$ & 21 & $(13.3 \%)$ & 11 & $(7.0 \%)$ & 29 & $(18.2 \%)$ \\
\hline Female & 150 & $(40.2 \%)$ & 24 & $(6.4 \%)$ & 28 & $(7.5 \%)$ & 62 & $(16.5 \%)$ \\
\hline By resident's age & \multicolumn{2}{|l|}{$N=205^{\mathrm{a}}$} & \multicolumn{2}{|l|}{$N=45$} & \multicolumn{2}{|l|}{$N=39$} & \multicolumn{2}{|l|}{$N=91$} \\
\hline $0-69$ & 15 & $(35.7 \%)$ & 4 & $(9.5 \%)$ & 4 & $(9.5 \%)$ & 10 & $(23.8 \%)$ \\
\hline $70-79$ & 33 & $(35.1 \%)$ & 12 & $(12.6 \%)$ & 4 & $(4.3 \%)$ & 16 & $(16.8 \%)$ \\
\hline $80-89$ & 107 & $(42.6 \%)$ & 21 & $(8.4 \%)$ & 22 & $(8.8 \%)$ & 39 & $(15.5 \%)$ \\
\hline $90+$ & 50 & $(35.5 \%)$ & 8 & $(5.7 \%)$ & 9 & $(6.4 \%)$ & 26 & $(18.3 \%)$ \\
\hline By result of transfer & \multicolumn{2}{|l|}{$N=202^{\mathrm{a}}$} & \multicolumn{2}{|l|}{$N=45$} & \multicolumn{2}{|l|}{$N=39$} & \multicolumn{2}{|l|}{$N=91$} \\
\hline ED visit & 62 & $(32.0 \%)$ & 22 & $(11.3 \%)$ & 8 & $(4.1 \%)$ & 33 & $(16.9 \%)$ \\
\hline Hospital admission & 140 & $(42.2 \%)$ & 23 & $(6.9 \%)$ & 31 & $(9.4 \%)$ & 58 & $(17.4 \%)$ \\
\hline By weekday of transfer & \multicolumn{2}{|l|}{$N=206$} & \multicolumn{2}{|l|}{$N=45$} & \multicolumn{2}{|l|}{$N=39$} & \multicolumn{2}{|l|}{$N=89^{\mathrm{a}}$} \\
\hline Monday & 37 & $(40.7 \%)$ & 7 & $(7.6 \%)$ & 8 & $(8.8 \%)$ & 14 & $(15.2 \%)$ \\
\hline Tuesday & 30 & $(38.5 \%)$ & 5 & $(6.4 \%)$ & 3 & $(3.9 \%)$ & 15 & $(19.2 \%)$ \\
\hline Wednesday & 33 & $(42.3 \%)$ & 10 & $(12.8 \%)$ & 6 & $(7.8 \%)$ & 15 & $(19.2 \%)$ \\
\hline Thursday & 46 & $(56.1 \%)$ & 6 & $(7.3 \%)$ & 0 & $(0.0 \%)$ & 10 & $(12.2 \%)$ \\
\hline Friday & 31 & $(43.7 \%)$ & 6 & $(8.5 \%)$ & 2 & $(2.8 \%)$ & 8 & $(11.0 \%)$ \\
\hline Saturday & 14 & $(25.9 \%)$ & 5 & $(9.3 \%)$ & 10 & $(18.5 \%)$ & 10 & $(18.5 \%)$ \\
\hline Sunday & 15 & $(19.7 \%)$ & 6 & $(7.9 \%)$ & 10 & $(13.2 \%)$ & 17 & $(22.4 \%)$ \\
\hline By time of transfer & \multicolumn{2}{|l|}{$N=204^{\mathrm{a}}$} & \multicolumn{2}{|l|}{$N=45$} & $N=39$ & & $N=91$ & \\
\hline 07:00am-12:59 pm & 79 & $(40.7 \%)$ & 6 & $(3.1 \%)$ & 14 & $(7.2 \%)$ & 31 & $(15.9 \%)$ \\
\hline 01:00 pm-05:59 pm & 83 & $(45.9 \%)$ & 27 & $(14.9 \%)$ & 12 & $(6.7 \%)$ & 31 & $(17.0 \%)$ \\
\hline 06:00 pm-10:59 pm & 25 & $(32.1 \%)$ & 6 & $(7.7 \%)$ & 5 & $(6.4 \%)$ & 13 & $(16.7 \%)$ \\
\hline $11: 00 \mathrm{pm}-06: 59 \mathrm{am}$ & 17 & $(23.3 \%$ & 6 & $(8.2 \%)$ & 8 & $(11.0 \%)$ & 16 & $(21.6 \%)$ \\
\hline By reasons (symptoms) & $N=206$ & & $N=45$ & & $N=39$ & & $N=91$ & \\
\hline $\begin{array}{l}\text { Deterioration of health status (e.g. fever, infection, dyspnea, exsic- } \\
\text { cosis) }\end{array}$ & 98 & $(52.1 \%)$ & 9 & $(4.8 \%)$ & 19 & $(10.1 \%)$ & 31 & $(16.5 \%)$ \\
\hline Fall/accident/injury & 41 & $(23.0 \%)$ & 14 & $(7.9 \%)$ & 4 & $(2.3 \%)$ & 28 & $(15.6 \%)$ \\
\hline Psychiatric/neurologic disorders (e.g. challenging behavior, stroke) & 14 & $(36.8 \%)$ & 5 & $(13.2 \%)$ & 1 & $(2.6 \%)$ & 8 & $(21.1 \%)$ \\
\hline Complications with catheter/tube (e.g. blood in urine) & 7 & $(18.4 \%)$ & 10 & $(26.3 \%)$ & 3 & $(7.9 \%)$ & 10 & $(26.3 \%)$ \\
\hline Pain, not fall-induced & 17 & $(51.5 \%)$ & 1 & $(3.0 \%)$ & 4 & $(12.1 \%)$ & 5 & $(15.2 \%)$ \\
\hline Others (e.g. gastrointestinal symptoms, bleedings) & 29 & $(50.9 \%)$ & 6 & $(10.3 \%)$ & 8 & $(14.3 \%)$ & 9 & $(15.3 \%)$ \\
\hline By duration of symptoms & $N=205^{\mathrm{a}}$ & & $N=45$ & & $N=38^{\mathrm{a}}$ & & $N=88^{\mathrm{a}}$ & \\
\hline Less than $4 \mathrm{~h}$ & 78 & $(24.5 \%)$ & 23 & $(7.2 \%)$ & 17 & $(5.4 \%)$ & 52 & $(16.3 \%)$ \\
\hline Between 4 and $12 \mathrm{~h}$ & 41 & $(53.3 \%)$ & 6 & $(7.8 \%)$ & 8 & $(10.4 \%)$ & 13 & $(16.9 \%)$ \\
\hline Between 12 and $24 \mathrm{~h}$ & 31 & $(57.4 \%)$ & 5 & $(9.3 \%)$ & 7 & $(13.0 \%)$ & 13 & $(24.1 \%)$ \\
\hline Between 25 and $72 \mathrm{~h}$ & 19 & $(76.0 \%)$ & 2 & $(8.0 \%)$ & 4 & $(16.0 \%)$ & 3 & $(12.0 \%)$ \\
\hline Longer than $72 \mathrm{~h}$ & 36 & $(70.6 \%)$ & 9 & $(17.3 \%)$ & 2 & $(3.9 \%)$ & 7 & $(13.2 \%)$ \\
\hline By residents' wish for end-of-life care & $N=205^{\mathrm{a}}$ & & $N=45$ & & $N=38^{\mathrm{a}}$ & & $N=90^{\mathrm{a}}$ & \\
\hline Unknown & 108 & $(38.4 \%)$ & 22 & $(7.8 \%)$ & 23 & $(8.2 \%)$ & 49 & $(17.4 \%)$ \\
\hline Advance directive available & 97 & $(39.3 \%)$ & 23 & $(9.3 \%)$ & 15 & $(6.1 \%)$ & 41 & $(16.5 \%)$ \\
\hline
\end{tabular}

EMS Emergency Medical Services, EP emergency physician, GP general practitioner

${ }^{a}$ Only transfers with prior contacts are displayed, multiple contacts possible; numbers varied due to missing values

For example: GPs were contacted in $35.4 \%$ of transfers when residents were male 
Table 3 Involvement of GPs, residents, family members and legal guardians in transfer decision—by resident and transfer characteristics ${ }^{\mathrm{a}}$

\begin{tabular}{|c|c|c|c|c|c|c|c|c|}
\hline & \multirow{2}{*}{$\frac{\mathrm{GP}^{\mathrm{b}}}{N}$} & & \multicolumn{2}{|l|}{ Resident $^{\mathrm{c}}$} & \multicolumn{2}{|c|}{ Family member ${ }^{c}$} & \multicolumn{2}{|c|}{ Legal guardian $^{\mathrm{c}}$} \\
\hline & & & $N$ & & $N$ & & $N$ & \\
\hline Involvement in all transfer decisions & 185 & $(34.8 \%)$ & 498 & $(95.8 \%)$ & 397 & $(78.8 \%)$ & 195 & $(42.4 \%)$ \\
\hline Involvement by & & & & & & & & \\
\hline Resident's sex & $N=185$ & & $N=498$ & & $N=396^{\mathrm{a}}$ & & $N=194^{\mathrm{a}}$ & \\
\hline Male & 53 & $(33.5 \%)$ & 149 & $(94.9 \%)$ & 114 & $(75.5 \%)$ & 59 & $(43.1 \%)$ \\
\hline Female & 132 & $(35.3 \%)$ & 349 & $(96.1 \%)$ & 282 & $(80.1 \%)$ & 135 & $(41.9 \%)$ \\
\hline Resident's age & $N=185$ & & $N=494^{\mathrm{a}}$ & & $N=393^{\mathrm{a}}$ & & $N=193^{\mathrm{a}}$ & \\
\hline $0-69$ & 13 & $(31.7 \%)$ & 38 & $(90.5 \%)$ & 25 & $(64.1 \%)$ & 19 & $(50.0 \%$ \\
\hline $70-79$ & 26 & $(27.7 \%)$ & 84 & $(96.6 \%)$ & 66 & $(75.0 \%)$ & 35 & $(45.4 \%)$ \\
\hline $80-89$ & 93 & $(37.1 \%)$ & 238 & $(96.4 \%)$ & 191 & $(81.6 \%)$ & 99 & $(46.0 \%)$ \\
\hline $90+$ & 53 & $(37.3 \%)$ & 134 & $(95.7 \%)$ & 111 & $(79.9 \%)$ & 40 & $(31.5 \%)$ \\
\hline Result of transfer & $N=181^{\mathrm{a}}$ & & $N=493^{\mathrm{a}}$ & & $N=392^{\mathrm{a}}$ & & $N=192^{\mathrm{a}}$ & \\
\hline ED visit & 46 & $(23.7 \%)$ & 184 & $(96.3 \%)$ & 127 & $(71.7 \%)$ & 57 & $(35.2 \%)$ \\
\hline Hospital admission & 135 & $(40.7 \%)$ & 309 & $(95.7 \%)$ & 265 & $(82.3 \%)$ & 135 & $(45.9 \%)$ \\
\hline Weekday of transfer & $N=185$ & & $N=498$ & & $N=396^{\mathrm{a}}$ & & $N=194^{\mathrm{a}}$ & \\
\hline Monday & 31 & $(33.7 \%)$ & 86 & $(94.5 \%)$ & 63 & $(73.3 \%)$ & 29 & $(36.7 \%)$ \\
\hline Tuesday & 33 & $(42.3 \%)$ & 70 & $(90.9 \%)$ & 58 & $(78.4 \%)$ & 29 & $(43.9 \%)$ \\
\hline Wednesday & 32 & $(41.0 \%)$ & 73 & $(97.3 \%)$ & 63 & $(85.1 \%)$ & 26 & $(37.7 \%)$ \\
\hline Thursday & 39 & $(47.6 \%)$ & 80 & $(98.8 \%)$ & 63 & $(82.9 \%)$ & 36 & $(50.7 \%)$ \\
\hline Friday & 31 & $(43.7 \%)$ & 68 & $(98.6 \%)$ & 49 & $(73.1 \%)$ & 24 & $(38.7 \%)$ \\
\hline Saturday & 8 & $(14.8 \%)$ & 50 & $(94.3 \%)$ & 38 & $(74.5 \%)$ & 17 & $(36.2 \%)$ \\
\hline Sunday & 11 & $(14.5 \%)$ & 71 & $(97.3 \%)$ & 62 & $(83.8 \%)$ & 33 & $(51.6 \%)$ \\
\hline Time of transfer & $N=182^{\mathrm{a}}$ & & $N=492^{\mathrm{a}}$ & & $N=392^{\mathrm{a}}$ & & $N=192^{\mathrm{a}}$ & \\
\hline 07:00am-12:59 pm & 84 & $(43.5 \%)$ & 182 & $(96.3 \%)$ & 149 & $(78.8 \%)$ & 84 & $(47.2 \%)$ \\
\hline 01:00 pm-05:59 pm & 80 & $(44.0 \%)$ & 170 & $(95.5 \%)$ & 142 & $(83.5 \%)$ & 66 & $(43.1 \%)$ \\
\hline $06: 00 \mathrm{pm}-10: 59 \mathrm{pm}$ & 16 & $(20.5 \%)$ & 74 & $(97.4 \%)$ & 60 & $(82.2 \%)$ & 27 & $(41.5 \%)$ \\
\hline 11:00 pm-06:59am & 2 & $(2.7 \%)$ & 66 & $(93.0 \%)$ & 41 & $(61.2 \%)$ & 15 & $(25.4 \%)$ \\
\hline Reasons (symptoms) & $N=185$ & & $N=498$ & & $N=397^{\mathrm{a}}$ & & $N=195$ & \\
\hline $\begin{array}{l}\text { Deterioration of health status (e.g. fever, infection, dyspnea, } \\
\text { exsiccosis) }\end{array}$ & 98 & $(52.4 \%)$ & 174 & $(94.6 \%)$ & 139 & $(77.2 \%)$ & 76 & $(46.6 \%)$ \\
\hline Fall/accident/injury & 29 & $(16.3 \%)$ & 171 & $(97.7 \%)$ & 131 & $(79.9 \%)$ & 59 & $(38.1 \%)$ \\
\hline $\begin{array}{l}\text { Psychiatric/neurologic disorders (e.g. challenging behavior, } \\
\text { stroke) }\end{array}$ & 13 & $(35.1 \%)$ & 33 & $(94.3 \%)$ & 32 & $(86.5 \%)$ & 20 & $(57.1 \%)$ \\
\hline Complications with catheter/tube (e.g. blood in urine) & 6 & $(15.8 \%)$ & 36 & $(97.3 \%)$ & 23 & $(63.9 \%)$ & 7 & $(22.6 \%)$ \\
\hline Pain, not fall-induced & 15 & $(45.5 \%)$ & 32 & $(97.0 \%)$ & 26 & $(83.9 \%)$ & 12 & $(44.4)$ \\
\hline Others (e.g. gastrointestinal symptoms, bleedings) & 24 & $(40.7 \%)$ & 52 & $(92.9 \%)$ & 46 & $(82.1 \%)$ & 21 & $(42.9 \%)$ \\
\hline Duration of symptoms & $N=184^{\mathrm{a}}$ & & $N=492^{\mathrm{a}}$ & & $N=393^{\mathrm{a}}$ & & $N=192^{\mathrm{a}}$ & \\
\hline Less than $4 \mathrm{~h}$ & 56 & $(17.7 \%)$ & 296 & $(96.1 \%)$ & 230 & $(78.2 \%)$ & 103 & $(38.4 \%)$ \\
\hline Between 4 and $12 \mathrm{~h}$ & 42 & $(54.6 \%)$ & 71 & $(93.4 \%)$ & 63 & $(82.9 \%)$ & 36 & $(50.0 \%)$ \\
\hline Between 12 and $24 \mathrm{~h}$ & 30 & $(55.6 \%)$ & 52 & $(96.3 \%)$ & 42 & $(79.2 \%)$ & 21 & $(44.7 \%)$ \\
\hline Between 25 and $72 \mathrm{~h}$ & 19 & $(76.0 \%)$ & 22 & $(91.7 \%)$ & 20 & $(83.3 \%)$ & 9 & $(42.9 \%)$ \\
\hline Longer than $72 \mathrm{~h}$ & 37 & $(69.8 \%)$ & 51 & $(98.1 \%)$ & 38 & $(74.5 \%)$ & 23 & $(48.9 \%)$ \\
\hline Residents' wishes for end-of-life care & $N=184^{\mathrm{a}}$ & & $N=496^{\mathrm{a}}$ & & $N=394^{\mathrm{a}}$ & & $N=194^{\mathrm{a}}$ & \\
\hline Unknown & 100 & $(35.7 \%)$ & 266 & $(95.7 \%)$ & 194 & $(72.7 \%)$ & 112 & $(44.3 \%)$ \\
\hline Advance directive available & 84 & $(33.9 \%)$ & 230 & $(95.8 \%)$ & 200 & $(85.8 \%)$ & 82 & $(40.0 \%)$ \\
\hline
\end{tabular}


Table 3 (continued)

EMS Emergency Medical Services, EP emergency physician, GP general practitioner

${ }^{a}$ Only transfers with involvement of the GP, residents, family members and legal guardians are displayed; multiple answer possible; numbers varied due to missing values

For example: GPs were involved in $33.5 \%$ of transfer decision when residents were male

${ }^{\mathrm{b}} \mathrm{GP}$ involved via telephone or $\mathrm{NH}$ visit

${ }^{\mathrm{c}}$ Involved in decision or informed about transfer

Fig. 1 Weekday and time of transfers $(n=533)$. *Number of transfers differed between weekdays; Monday $(n=92 ; 17.2 \%)$, Tuesday $(n=78 ; 14.6 \%)$, Wednesday $(n=78 ; 14.6 \%)$, Thursday $(n=82 ; 15.3 \%)$, Friday $(n=73 ; 13.6 \%)$, Saturday $(n=54 ; 10.1 \%)$, Sunday $(n=76$; $14.2 \%)$

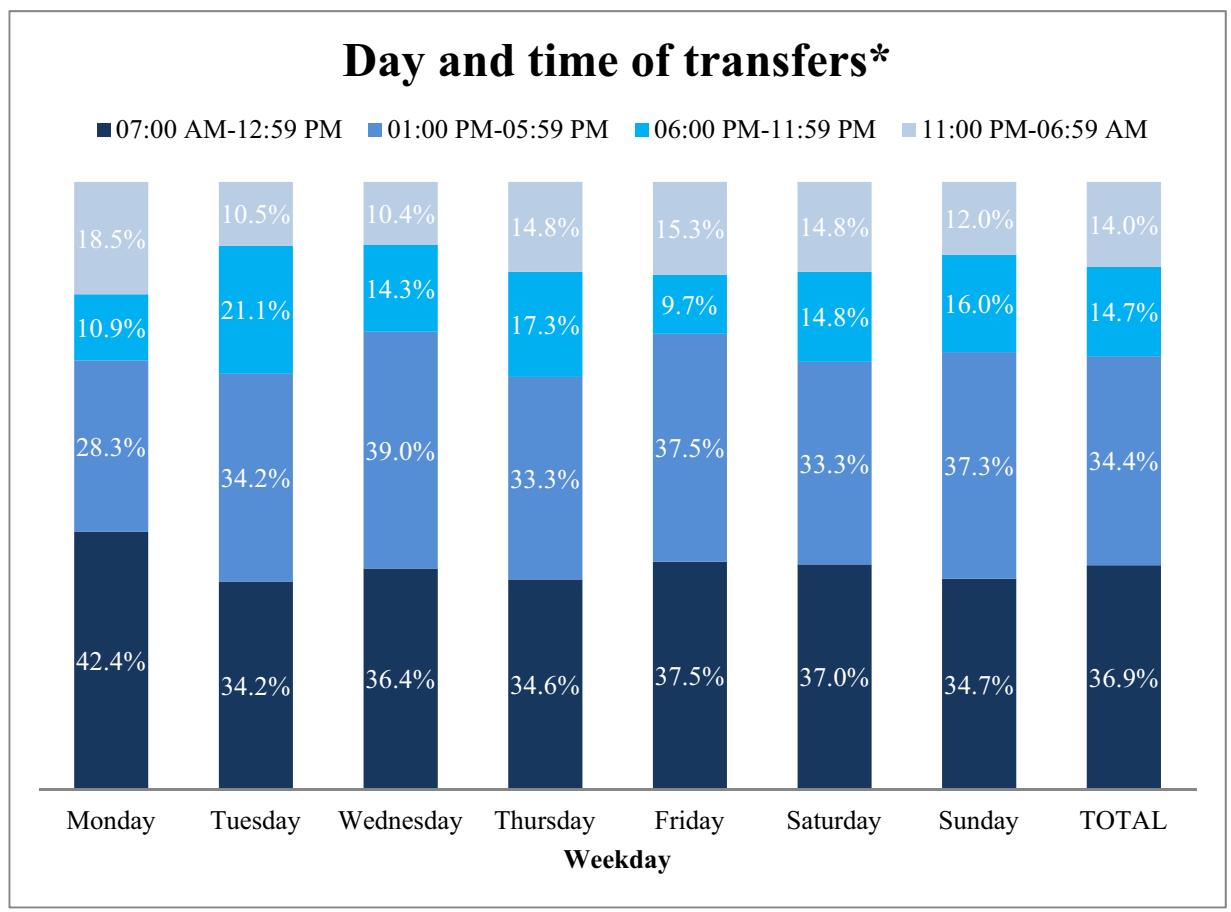

*number of transfers differed between weekdays; Monday ( $n=92 ; 17.2 \%)$, Tuesday ( $n=78 ; 14.6 \%)$, Wednesday ( $n=78 ; 14.6 \%)$, Thursday $(n=82 ; 15.3 \%)$, Friday $(n=73 ; 13.6 \%)$, Saturday $(n=54$; $10.1 \%)$, Sunday $(n=76 ; 14.2 \%)$ in $62.3 \%$ (range between NHs: $38.9 .3-92.8 \%$ ). If legal guardians were available $(n=238)$, they were informed only in $66.8 \%$ (directly involved in $15.1 \%$ ). For details see Table 3 (only transfers with prior involvement are displayed).

Focusing on transfers which were carried out during working hours when GPs and specialists are potentially available for consultation (Monday, Tuesday, Thursday, Friday 08:00am-05:59 pm and Wednesday 08:00am-12:59 pm), we could identify $n=254$ transfers (47.5\%). Nevertheless, in only $53.5 \%$ of those transfers the GPs were involved in the final transfer decision (via telephone: $31.3 \%$, via $\mathrm{NH}$ visit: $22.2 \%$ ). In $30.2 \%$ nursing staff did not make any attempt to contact the GP and in $16.3 \%$ the GP was not available. These rates of non-involvement varied also among the NHs and ranged between $0.0 \%$ and $54.5 \%$ (because of no contact) and $0.0-37.5 \%$ (because of lacking availability).

\section{Discussion}

In our study, we assessed the characteristics of unplanned hospital transfers of NHRs and circumstances prior to a transfer. Deterioration of health status and falls/accidents/ injuries were identified as the main reasons leading to a transfer. The majority of transfers happened without the involvement of the GP and the relevance of other physicians (specialists or OOHC) was low. We found that NHRs themselves were involved in the transfer decision in $45.8 \%$ of cases. Family members and legal guardians were more often informed about the transfer rather than involved in the decision.

\section{Physician contacts and involvement of the GP}

Deteriorations of health status and falls were also reported in other studies as reasons for hospital transfers among NHRs [4, 16, 33]. These symptoms can often be managed 
in ambulatory care. However, the management by physicians appears to be low in our study. In nearly half of the cases, there was no prior contact to any health care provider in the $48 \mathrm{~h}$ prior to an ambulance call and residents were directly transferred to hospital. This is in line with findings reported by Briggs et al. [34]. In this context, low contacts to specialists and the OOHC seem to be not surprising due to the fact that $\mathrm{NH}$ visits by specialists are-depending on their specialization-insufficient in Germany $[35,36]$ and the financial compensation for participating in the OOHC is criticized as too low by physicians [13]. Both facts may contribute to the low presence/relevance of these physicians in the management of NHRs' health changes.

Even without a formal gatekeeper system in Germany, the GP is primarily responsible for care decisions of NHRs. However, in our study GPs were contacted in the $48 \mathrm{~h}$ prior to a transfer in only $38.7 \%$ of cases. Later during transfer decision, the GP was involved in only every third case. This noninvolvement cannot be traced back on life-threatening conditions which require quick reactions. In our study, mainly falls were reasons for transfers which do not always require hospital care. Other studies discuss in this context the insufficient availability of physicians [16, 32]. We found that even during GP working hours-when availability can be assumed - nursing staff did not make any attempt to contact the GP for a final transfer decision in $30.2 \%$ of cases. Similar observations of low pre-transfer contacts to the GP were reported in several other studies [29, 34, 37-39]. Because the EMS in Germany is not allowed to make a medical diagnosis, they are often trapped in a situation of uncertainty. Being send by a dispatcher, without official authority to make a diagnosis they are obliged to transport every patient to hospital [40]. We also found high differences between the NHs. These marked differences indicate the impact of organizational factors contributing to unplanned transfers. Günther et al. [41] showed in this context that the number of involved physicians, intervals of routine visits or presence of advance care planning (ACP) might have an impact on physicians' involvement and transfers of NHRs. However, we have no detailed information on $\mathrm{NH}$ characteristics (staffing, for example). Other contributing factors might be the workload and internal instructions in each facility. When calling an ambulance, the NHR will be transferred to hospital without the need of further waiting, discussing and organizing a contact with a physician. Nursing staff might therefore tend to get rid of some residents and can consequently also avoid additional care [16, 42]. This problem might be more apparent in NHs with high workload and nursing staff with limited competence than in NHs which have the capacities to manage symptoms on-site. Additionally, the fear of legal consequences can be represented differently in the $\mathrm{NH}$ which is often a main trigger for nursing staff to call the ambulance [32, 43, 44]. Transfers initiated based on these reasons might be avoidable [20, 45, 46].

\section{Involvement of NHRs, family members and legal guardians}

In view of nursing staff, NHRs' wishes and quality of life are rated as highly influential for transfer decision [47, 48]. In our study, NHRs themselves were more informed about the upcoming transfer than involved in the decision. On the one hand, the high prevalence of dementia (51.3\%) can have an influence when the need for a transfer and residents' wishes cannot be communicated adequately. On the other hand, ADs with documented residents' wishes for end-of-life care were available in just $46.9 \%$. In more than half of the cases, nursing staff was therefore faced with the challenge to act in the NHRs' best interest without knowledge about their preferences. This problem was also reported in other studies [16, 49]. As a consequence, nursing staff could mainly rely on the view of family members and legal guardians which were considered in several studies as having high influence on transfer decisions $[27,47,50,51]$. However, in our study family members were more informed about the transfer than actually involved in the decision ( $62.3 \%$ vs. $21.8 \%$ ). A main reason could be the short time period between the onset of symptoms and initiation of the transfer, which mainly lasted less than $4 \mathrm{~h}(60.4 \%)$. More importantly, we do not know if this non-involvement may be desired by family members. We assume that structured ACP discussions in NHs are fundamentally important to communicate and document preferences of residents and family members together with nursing staff and physicians. This implies more than the existence of ADs because they alone cannot guarantee a prevention of a hospital transfer [52, 53]. But so far, the concept of ACP is not established in Germany in contrast to other countries, such as the USA or Canada [54].

\section{Implications for practice}

Main findings are a low degree of GP involvement in transfer decisions and marked differences between nursing homes regarding the involvement. Structural differences might explain these findings and can be part of the solution at the same time. In Germany, NHRs are cared for by an average of 8.6 different GPs [35]. A reduced number of responsible GPs might improve the collaboration and coordination of care leading to a reduction of transfers from NHs [27]. In the Netherlands for example, 'elderly care physicians' with a 3-year training program are employed in NHs to care for all residents on-site [12, 55, 56]. They have the potential to monitor health changes more closely which can prevent deteriorations of health status. In Germany, there is one model project which realized this concept of a NH physician and showed a reduction of hospital transfers and health care costs $[57,58]$. However, it is still not part of regular health care. In other countries, nurse practitioners or specialist nurses, as established in the USA for example $[12,35,55$, 56] perform in the first-line assessment of residents which is 
correlated with fewer hospital transfers [59-62]. In Germany, these professional groups are not established due to the legal right to choose the GP freely and nursing staffs' limited rights in medical care. Because nursing staff often fear legal consequences [32, 43], we assume that legal relaxations of personal liability could encourage nursing staff to more responsibility leading to a reduction of transfers. In general, there is a need for more personal in NHs to decrease workload, as criticized in other studies as a reasonfor hospital transfers [32].

\section{Strengths and limitations}

With our study we provide current data on hospital transfers from NHs in Germany. However, some limitations have to be considered. Due to data anonymization, we can only provide information based on transfers (and not on residents). Further, we have no information on not-transported residents. Analysis based on resident-level (for example frequency of multiple transfers or the relationship between age/frailty and transfers) was not possible- but also not the aim of the study. A high proportion of cases were documented in three $\mathrm{NHs}$ because all residents of these facilities were included. This may increase the risk of selection bias. Even though most information was based on existing medical records, a recall-bias cannot be excluded. Additionally, there might the risk of an underreporting when nursing staff have forgotten to document a transfer. We therefore reminded nursing staff regularly to document each transfer immediately after each event. Despite recruiting NHs with different locations, sizes and ownerships, a selection of the sample is still possible due to voluntary participation and payment of financial compensation. The generalizability of our data can be therefore limited-also in comparison to other regions of Germany or health care systems in other countries. Nevertheless, this is the first study providing insights into contacts to physicians and involvement of relevant others prior to a transfer from NHs.

\section{Conclusions}

Our study provides recent data on hospital transfers of NHRs in Germany. Specialists and OOHC physicians are rarely contacted prior to an ambulance call and the involvement of the GP in the transfer decision is low. This occurs also during working hours when the availability of physicians can be assumed. The lack of medical consultation and differences in the organizational procedures of $\mathrm{NHs}$ may therefore contribute to potentially avoidable hospital transfers. Further research is needed to explore nursing staffs' reasons for this non-involvement and possible organizational procedures in detail. There is further a need for a close monitoring of health changes to improve care of NHRs. According to experiences of other countries,
$\mathrm{NH}$ physicians or specialized nurses can have a positive impact on managing symptoms on-site which might reduce burden transfers to hospital. In more than half of the transfers, NHRs wishes for end-of-life care were unknown. However, relevant others as family members and legal guardians were not always actively involved in the transfer decision instead. Structured and regular ACP discussions might improve communication and can ensure that all nursing staff is aware of individual care wishes before an ambulance is called.

Acknowledgements We thank the nursing homes for their participation in our study and Falk Hoffmann for commenting on the manuscript. Special thanks go to Mareike Würdemann and Merlin Wenzel for their support in entering and controlling the data.

Author contributions The concept of the study was planned and discussed by all project members. AP and AMF were responsible for the coordination of the study including recruitment of the nursing homes and data collection. GS provided clinical expertise. AP and AMF analyzed data. The manuscript was written by AP and critically revised by AMF and GS. All authors reviewed and approved the final version.

Funding Open Access funding enabled and organized by Projekt DEAL. This study is part of the project 'HOMERN' focusing on hospital admissions and ED visits of nursing home residents in Germany. This work was supported by the Innovation Fund coordinated by the Innovation Committee of the Federal Joint Committee (G-BA) in Germany (Innovationsausschuss beim Gemeinsamen Bundesausschuss, G-BA) (FKZ/Grant Number: 01VSF16055) and had no influence on the content of the paper and the publication process.

Data availability The datasets generated during and/or analyzed during the current study are available from the corresponding author on reasonable request.

\section{Compliance with ethical standards}

Conflict of interest The authors have no conflicts of interest to declare that are relevant to the content of this article.

Ethical approval Ethical approval for this study was waived by the local ethics committee of the Medical Association of Bremen (RA/RE-613, 16 February 2018).

Statement of human and animal rights This article does not contain any studies with human participants or animals performed by any of the authors.

Informed consent Written informed consent was obtained from all NHs prior to their study inclusion.

Open Access This article is licensed under a Creative Commons Attribution 4.0 International License, which permits use, sharing, adaptation, distribution and reproduction in any medium or format, as long as you give appropriate credit to the original author(s) and the source, provide a link to the Creative Commons licence, and indicate if changes were made. The images or other third party material in this article are included in the article's Creative Commons licence, unless indicated otherwise in a credit line to the material. If material is not included in the article's Creative Commons licence and your intended use is not permitted by statutory regulation or exceeds the permitted use, you will 
need to obtain permission directly from the copyright holder. To view a copy of this licence, visit http://creativecommons.org/licenses/by/4.0/.

\section{References}

1. Gordon AL, Franklin M, Bradshaw L et al (2014) Health status of UK care home residents: a cohort study. Age Ageing 43:97-103. https://doi.org/10.1093/ageing/aft077

2. Dwyer R, Gabbe B, Stoelwinder JU et al (2014) A systematic review of outcomes following emergency transfer to hospital for residents of aged care facilities. Age Ageing 43:759-766. https:// doi.org/10.1093/ageing/afu117

3. Grabowski DC, Stewart KA, Broderick SM et al (2008) Predictors of nursing home hospitalization: a review of the literature. Med Care Res Rev 65:3-39. https://doi.org/10.1177/107755870730875 4

4. Graverholt B, Riise T, Jamtvedt G et al (2011) Acute hospital admissions among nursing home residents: a population-based observational study. BMC Health Serv Res 11:126. https://doi. org/10.1186/1472-6963-11-126

5. Hoffmann F, Allers K (2016) Age and sex differences in hospitalisation of nursing home residents: a systematic review. BMJ Open 6:e011912. https://doi.org/10.1136/bmjopen-2016-011912

6. Trivedi S, Roberts C, Karreman E et al (2018) Characterizing the long-term care and community-dwelling elderly patients' use of the emergency department. Cureus 10:e3642-e3642. https://doi. org/10.7759/cureus.3642

7. Allers K, Hoffmann F (2018) Mortality and hospitalization at the end of life in newly admitted nursing home residents with and without dementia. Soc Psychiatry Psychiatr Epidemiol 53:833839. https://doi.org/10.1007/s00127-018-1523-0

8. Hoffmann F, Allers K (2017) Variations over time in the effects of age and sex on hospitalization rates before and after admission to a nursing home: a German cohort study. Maturitas 102:50-55. https://doi.org/10.1016/j.maturitas.2017.04.017

9. Brucksch A, Hoffmann F, Allers K (2018) Age and sex differences in emergency department visits of nursing home residents: a systematic review. BMC Geriatr 18:151-151. https://doi.org/10.1186/ s12877-018-0848-6

10. Ouslander JG, Lamb G, Perloe M et al (2010) Potentially avoidable hospitalizations of nursing home residents: frequency, causes, and costs: (see editorial comments by Drs. Jean F. Wyman and William R. Hazzard, pp 760-761). J Am Geriatr Soc 58:627-635. https://doi.org/10.1111/j.1532-5415.2010.02768.x

11. Schmiemann G, Herget-Rosenthal S, Hoffmann F (2016) Ärztliche Versorgung von Pflegeheimbewohnern. Zeitschrift für Gerontologie und Geriatrie 49:727-733. https://doi.org/10.1007/s0039 1-015-1010-0

12. Koopmans RTCM, Lavrijsen JCM, Hoek JF et al (2010) Dutch elderly care physician: a new generation of nursing home physician specialists. J Am Geriatr Soc 58:1807-1809. https://doi.org /10.1111/j.1532-5415.2010.03043.x

13. Frankenhauser-Mannuss J, Goetz K, Scheuer M et al (2014) Outof-hours primary care in Germany: general practitioners' views on the current situation. Gesundheitswesen 76:428-433. https:// doi.org/10.1055/s-0034-1367020

14. Carron PN, Dami F, Yersin B et al (2015) Increasing prehospital emergency medical service interventions for nursing home residents. Swiss Med Wkly 145:w14126. https://doi.org/10.4414/ smw.2015.14126

15. Bundesanstalt für Straßenwesen (2011) Einsatzfahrtaufkommen im öffentlichen Rettungsdienst in Prozent (primary source: (primary source: German Federal Statistical Office). www.gbe-bund. de (keywords: Rettungsdienst $\rightarrow$ art of document: Grafiken). Accessed 09 Oct 2019

16. Lemoyne SE, Herbots HH, De Blick D et al (2019) Appropriateness of transferring nursing home residents to emergency departments: a systematic review. BMC Geriatr 19:17. https:// doi.org/10.1186/s12877-019-1028-z

17. Cardona-Morrell M, Kim JCH, Brabrand M et al (2017) What is inappropriate hospital use for elderly people near the end of life? A systematic review. Eur J Intern Med 42:39-50. https://doi. org/10.1016/j.ejim.2017.04.014

18. Renom-Guiteras A, Uhrenfeldt L, Meyer G et al (2014) Assessment tools for determining appropriateness of admission to acute care of persons transferred from long-term care facilities: a systematic review. BMC Geriatr 14:80. https://doi. org/10.1186/1471-2318-14-80

19. Morphet J, Innes K, Griffiths DL et al (2015) Resident transfers from aged care facilities to emergency departments: can they be avoided? Emerg Med Australas 27:412-418. https://doi. org/10.1111/1742-6723.12433

20. Carron PN, Mabire C, Yersin B et al (2017) Nursing home residents at the Emergency Department: a 6-year retrospective analysis in a Swiss academic hospital. Intern Emerg Med 12:229-237. https://doi.org/10.1007/s11739-016-1459-x

21. Saliba D, Kington R, Buchanan J et al (2000) Appropriateness of the decision to transfer nursing facility residents to the hospital. J Am Geriatr Soc 48:154-163. https://doi. org/10.1111/j.1532-5415.2000.tb03906.x

22. Theou O, Sluggett JK, Bell JS et al (2017) Frailty, hospitalization, and mortality in residential aged care. J Gerontol Ser A 73:1090-1096. https://doi.org/10.1093/gerona/glx185

23. Trahan LM, Spiers JA, Cummings GG (2016) Decisions to transfer nursing home residents to emergency departments: a scoping review of contributing factors and staff perspectives. J Am Med Dir Assoc 17:994-1005. https://doi.org/10.1016/j. jamda.2016.05.012

24. Laging B, Ford R, Bauer M et al (2015) A meta-synthesis of factors influencing nursing home staff decisions to transfer residents to hospital. J Adv Nurs 71:2224-2236. https://doi. org/10.1111/jan.12652

25. Arendts G, Reibel T, Codde J et al (2010) Can transfers from residential aged care facilities to the emergency department be avoided through improved primary care services? Data from qualitative interviews. Australas J Ageing 29:61-65. https://doi. org/10.1111/j.1741-6612.2009.00415.x

26. Unroe KT, Hickman SE, Carnahan JL et al (2018) Investigating the avoidability of hospitalizations of long stay nursing home residents: opportunities for improvement. Innov Aging 2:igy017. https://doi.org/10.1093/geroni/igy017

27. Pulst A, Fassmer AM, Schmiemann G (2019) Experiences and involvement of family members in transfer decisions from nursing home to hospital: a systematic review of qualitative research. BMC Geriatr 19:155. https://doi.org/10.1186/s1287 7-019-1170-7

28. von Elm E, Altman DG, Egger M et al (2008) The strengthening the reporting of observational studies in epidemiology (STROBE) statement: guidelines for reporting observational studies. J Clin Epidemiol 61:344-349. https://doi.org/10.1016/j.jclin epi.2007.11.008

29. Kada O, Janig H, Likar R et al (2017) Reducing avoidable hospital transfers from nursing homes in austria: project outline and baseline results. Gerontol Geriatr Med 3:2333721417696671. https:// doi.org/10.1177/2333721417696671

30. Bradford A, Kunik ME, Schulz P et al (2009) Missed and delayed diagnosis of dementia in primary care: prevalence and contributing factors. Alzheimer Dis Assoc Disord 23:306-314. https://doi. org/10.1097/WAD.0b013e3181a6bebc 
31. Brüne-Cohrs U, Juckel G, Schröder SG (2007) Qualität der Demenzdiagnostik im Seniorenheim. Zeitschrift für ärztliche Fortbildung und Qualität im Gesundheitswesen-Ger J Qual Health Care 101:611-615. https://doi.org/10.1016/j.zgesu n.2007.09.009

32. Fassmer A, Pulst A, Schmiemann G et al (2020) Sex-specific differences in hospital transfers of nursing home residents: results from the hospitalizations and emergency department visits of nursing home residents (HOMERN) project. Int J Environ Res Public Health 17:3915. https://doi.org/10.3390/ijerph1711 3915

33. Krüger K, Jansen K, Grimsmo A et al (2011) Hospital admissions from nursing homes: rates and reasons. Nurs Res Pract. https:// doi.org/10.1155/2011/247623

34. Briggs R, Coughlan T, Collins R et al (2013) Nursing home residents attending the emergency department: clinical characteristics and outcomes. QJM 106:803-808. https://doi.org/10.1093/qjmed /hct136

35. Schröder A-K, Fassmer AM, Allers K et al (2020) Needs and availability of medical specialists' and allied health professionals' visits in German nursing homes: a cross-sectional study of nursing home staff. BMC Health Serv Res 20:332. https://doi.org/10.1186/ s12913-020-05169-7

36. Balzer K, Butz S, Bentzel J et al (2013) Beschreibung und Bewertung der fachärztlichen Versorgung von Pflegeheimbewohnern in Deutschland. HTA-Bericht 125:348

37. Gruneir A, Bell CM, Bronskill SE et al (2010) Frequency and pattern of emergency department visits by long-term care residents-a population-based study. J Am Geriatr Soc 58:510-517. https://doi. org/10.1111/j.1532-5415.2010.02736.x

38. Evans G (2011) Factors influencing emergency hospital admissions from nursing and residential homes: positive results from a practice-based audit. J Eval Clin Pract 17:1045-1049. https://doi. org/10.1111/j.1365-2753.2010.01471.x

39. Witt E, Goodman C, Banerjee A et al (2013) Patterns of attendance of care home residents to an Emergency Department. Eur J Emerg Med 20:136-137. https://doi.org/10.1097/MEJ.0b013 e32835608e 1

40. Pulst A, Fassmer AM, Hoffmann F et al (2020) Paramedics' perspectives on the hospital transfers of nursing home residents-a qualitative focus group study. Int J Environ Res Public Health. https://doi.org/10.3390/ijerph17113778

41. Günther A, Schmid S, Weidlich-Wichmann U et al (2019) Emergency care in nursing homes in the City of Braunschweig: a cross-sectoral view with indicators from deaths, resuscitation, emergency department visits and EMS deployment. Z Evid Fortbild Qual Gesundhwes 141-142:1-10. https://doi.org/10.1016/j. zefq.2019.02.010

42. McCloskey R, van den Hoonaard D (2007) Nursing home residents in emergency departments: a foucauldian analysis. J Adv Nurs 59:186-194. https://doi.org/10.1111/j.1365-2648.2007.04319.x

43. Kada O (2019) Hospital transfers of nursing home residents: a vignette experiment on nurses' decision making. J Appl Gerontol 38:499-509. https://doi.org/10.1177/0733464816687219

44. Shanley C, Whitmore E, Conforti D et al (2011) Decisions about transferring nursing home residents to hospital: highlighting the roles of advance care planning and support from local hospital and community health services. J Clin Nurs 20:2897-2906. https ://doi.org/10.1111/j.1365-2702.2010.03635.x

45. Lowthian JA, Cameron PA, Stoelwinder JU et al (2011) Increasing utilisation of emergency ambulances. Aust Health Rev 35:63-69. https://doi.org/10.1071/AH09866

46. Morley C, Unwin M, Peterson GM et al (2018) Emergency department crowding: a systematic review of causes, consequences and solutions. PLoS ONE 13:e0203316. https://doi.org/10.1371/journ al.pone. 0203316
47. Buchanan JL, Murkofsky RL, O’Malley AJ et al (2006) Nursing home capabilities and decisions to hospitalize: a survey of medical directors and directors of nursing. J Am Geriatr Soc 54:458-465. https://doi.org/10.1111/j.1532-5415.2005.00620.x

48. McDermott C, Coppin R, Little P et al (2012) Hospital admissions from nursing homes: a qualitative study of GP decision making. Br J Gen Pract 62:e538-545. https://doi.org/10.3399/bjgp12X653 589

49. Lopez RP (2009) Decision-making for acutely ill nursing home residents: nurses in the middle. J Adv Nurs 65:1001-1009. https ://doi.org/10.1111/j.1365-2648.2008.04958.x

50. George WM, Banat GA, Herrmann JJ et al (2017) Empirische Befunde zur Verlegungspraxis Sterbender. MMW Fortschritte der Medizin 159:6-14

51. Bottrell MM, O'Sullivan JF, Robbins MA et al (2001) Transferring dying nursing home residents to the hospital: DON perspectives on the nurse's role in transfer decisions. Geriatr Nurs 22:313-317. https://doi.org/10.1067/mgn.2001.120994

52. Nemiroff L, Marshall EG, Jensen JL et al (2019) Adherence to "No Transfer to Hospital" advance directives among nursing home residents. J Am Med Dir Assoc 20:1373-1381. https://doi. org/10.1016/j.jamda.2019.03.034

53. Cohen AB, Knobf MT, Fried TR (2017) Do-not-hospitalize orders in nursing homes: "call the family instead of calling the ambulance." J Am Geriatr Soc 65:1573-1577. https://doi.org/10.1111/ jgs. 14879

54. Richter-Kuhlmann E (2019) Advance care planning: bislang wenig gelebtes konzept. Dtsch Arztebl Int 116:A-2342

55. Koopmans R, Pellegrom M, van der Geer ER (2017) The Dutch move beyond the concept of nursing home physician specialists. J Am Med Dir Assoc 18:746-749. https://doi.org/10.1016/j.jamda .2017 .05 .013

56. Schols JM (2005) Nursing home medicine in The Netherlands. Eur J Gen Pract 11:141-143. https://doi.org/10.3109/1381478050 9178259

57. Richter-Reichhelm M, Müller RD (2004) Berliner Modellprojekt: Der Arzt am Pflegebett. Dtsch Arztebl Int 101:1482

58. Hibbeler B (2007) Ärztliche Versorgung in Pflegeheimen: Von Kooperationen profitieren alle. Dtsch Arztebl Int 104:3297

59. Kane RL, Flood S, Bershadsky B et al (2004) Effect of an innovative medicare managed care program on the quality of care for nursing home residents. Gerontologist 44:95-103. https://doi. org/10.1093/geront/44.1.95

60. McAiney CA, Haughton D, Jennings J et al (2008) A unique practice model for Nurse practitioners in long-term care homes. J Adv Nurs 62:562-571. https://doi.org/10.111 1/j.1365-2648.2008.04628.x

61. Christian R, Baker K (2009) Effectiveness of nurse practitioners in nursing homes: a systematic review. JBI Libr Syst Rev 7:1333-1352

62. Barker RO, Craig D, Spiers G et al (2018) Who should deliver primary care in long-term care facilities to optimize resident outcomes? a systematic review. J Am Med Dir Assoc 19:1069-1079. https://doi.org/10.1016/j.jamda.2018.07.006

Publisher's Note Springer Nature remains neutral with regard to jurisdictional claims in published maps and institutional affiliations. 